\title{
Behavioral Effects of Thebaine in the Rhesus Monkey ${ }^{1}$
}

\author{
JAMES H. WOODS ${ }^{2}$ \\ Department of Pharmacology, University of Michigan, Ann Arbor, MI 48109 \\ CHARLES R. SCHUSTER \\ Department of Psychiatry, University of Chicago
}

AND

CHRISTINE R. HARTEL

Department of Behavioral Sciences, University of Chicago

The University of Chicago, Pritzker School of Medicine

950 East 59th Street, Chicago, IL 60637

Received 10 January 1981

\begin{abstract}
WOODS, J. H., C. R. SCHUSTER AND C. R. HARTEL. Behavioral effects of the baine in the rhesus monkey. PHARMAC. BIOCHEM. BEHAV. 14(6) 805-809, 1981.-Three experiments were conducted with rhesus monkeys to assess some behavioral effects of the opium alkaloid, thebaine, in relation to its dependence liability. The concurrent intramuscular administration of naloxone did not antagonize the rate-decreasing effects of thebaine on a fixed-ratio (FR) schedule of food-reinforced responding. Animals trained to self-administer codeine $(0.3 \mathrm{mg} / \mathrm{kg} / \mathrm{inj})$ on an FR 30 schedule did not self-administer thebaine $(0.003-1.0 \mathrm{mg} / \mathrm{kg} / \mathrm{inj})$ at rates comparable to those of codeine. Rates were minimally above those of saline at $0.3 \mathrm{mg} / \mathrm{kg}$ inj. Monkeys given $23 \mathrm{hrs} /$ day continuous access to $1.0 \mathrm{mg} / \mathrm{kg} / \mathrm{inj}$ thebaine did, however, self-administer the drug at rates significantly higher than those maintained by saline, but not as high as those supported by $2.0 \mathrm{mg} / \mathrm{kg} / \mathrm{inj}$ codeine. Two animals self-administering thebaine did not show any signs of withdrawal when injected with $0.1-1.0 \mathrm{mg} / \mathrm{kg}$ of naloxone or when saline was substituted for thebaine. A third monkey showed a severe reaction leading to death following an injection of $1.0 \mathrm{mg} / \mathrm{kg}$ naloxone.
\end{abstract}

Thebaine Codeine Naloxone Food-reinforced responding

THEBAINE is an opium alkaloid which shows little, if any, analgesic action in common with morphine; although it does produce seizures [7]. Recent research interest in the pharmacology and the behavioral effects of thebaine has generated conflicting reports on its ability to produce dependence of the morphine type. Yanagita et al. [14] have reported that rhesus monkeys became physically dependent on thebaine as shown by naloxone and deprivation withdrawal tests. Thebaine, unlike codeine, did not suppress morphine withdrawal signs in morphine-dependent monkeys; rather, it produced signs resembling morphine withdrawal in these animals. Yanagita et al. [14] also reported that monkeys self-administered thebaine at rates higher than those for saline, but lower than those maintained by codeine.

Thebaine has not been found to produce physical dependence in other species. Harris [6] found no evidence of physical dependence in rats given continuous infusions of thebaine at various doses for a seven-day period and then abruptly withdrawn from the drug. Gilbert and Martin [4] reported that thebaine did not produce any morphine-like effects in non-dependent chronic spinal dogs. Thebaine did not precipitate an abstinence syndrome in morphinedependent dogs, although the authors pointed out that the excitatory actions of thebaine are similar to those of the withdrawal syndrome, and this might explain the interpretation of the signs reported by Yanagita et al. [14]. These authors did, however, note a slight effect of naloxone in the dog given chronic thebaine.

In an evaluation of the discriminative effects of narcotics in the rat [9], thebaine failed to produce morphine-like effects, while other narcotics did so.

The purpose of these experiments was to examine further the reinforcing effect of thebaine under two types of experimental conditions. In addition, observations were gathered

${ }^{1}$ Research supported by USPHS Grants DA0154, DA00254, and DA00250 from National Institute Drug Abuse following a request by the World Health Organization through Dr. Inayat Khan, Senior Medical Officer, Drug Dependence Unit, Mental Health Division.

${ }^{2}$ To whom reprint requests should be sent. 
on thebaine's direct effects on food-reinforced responding and the nature of the effects as revealed by antagonism studies with naloxone.

\section{GENERAL METHOD}

\section{Subjects}

Subjects in these experiments were 11 rhesus monkeys weighing between 5.0 and $8.0 \mathrm{~kg}$. The seven monkeys in experiments requiring intravenous drug self-administration were prepared with surgically implanted intravenous catheters [1]. These monkeys were permanently housed in their experimental cubicles, where they had free access to food and water. The remaining four monkeys were housed in individual housing cages. They were placed, for each experimental session, in primate restraining chairs which were inserted in sound-attenuated chambers with two response levers and an array of stimulus lights. These monkeys were deprived to $80 \%$ of their free-feeding weights and maintained at this level throughout this experiment. Experimental conditions were controlled and data recorded by automatic programming equipment located in an adjacent room.

\section{Drugs}

Thebaine ethanoate was dissolved and diluted in $0.9 \%$ saline solution. Thebaine $\mathrm{HCl}$ was dissolved in distilled water and buffered to a $\mathrm{pH}$ of 4.5 for use in Experiment 3 . Drug was prepared every other day. Doses of thebaine are expressed as the salts in Experiments 1 and 2; free base in Experiment 3. Codeine and naloxone were dissolved and diluted in $0.9 \%$ saline solution; doses are expressed as salts. All the intramuscularly administered drugs were injected into the thigh muscle in a volume of $1 \mathrm{cc}$. When two drugs were administered concurrently, injections were made a few seconds apart into different intramuscular sites.

\section{EXPERIMENT 1: THEBAINE AND ITS INTERACTION WITH NALOXONE \\ METHOD}

Four food-deprived monkeys were used that had an extensive history with the particular schedule of food presentation employed. Thirty responses on a key, mounted directly in front of the restraint chair, produced a $300 \mathrm{mg}$ banana-flavored food pellet. Following food delivery, the lights in the chamber changed and responses on the key delayed, for 30 additional sec, the condition in which 30 responses led to food presentation. Technically, this schedule of reinforcement [2] may be designated as a chain differential reinforcement of other behavior (DRO); fixed-ratio (FR). If 30 responses were not completed within $1 \mathrm{~min}$, the FR component was terminated and the DRO component came into effect. Each session lasted about one hour.

When behavior had stabilized on this schedule, animals were injected with saline or thebaine immediatley prior to the experimental session. Doses of thebaine were $0.32,1.0$, 1.78 , and $3.2 \mathrm{mg} / \mathrm{kg}$ and were given twice to each monkey in a mixed order. Subsequently, the two larger doses of thebaine were repeated, and on alternate drug administration sessions, naloxone $(0.1$ or $1.0 \mathrm{mg} / \mathrm{kg})$ was administered concurrently. In separate sessions, naloxone was given alone. As a positive control, prior to other sessions, morphine (3.2 $\mathrm{mg} / \mathrm{kg}$ ) was given to suppress the rates of responding and it was combined with naloxone $(0.03 \mathrm{mg} / \mathrm{kg})$.

\section{RESULTS}

Saline, 0.32 and $1.0 \mathrm{mg} / \mathrm{kg}$ thebaine did not affect response rates during the FR component of the schedule (Fig. la). The two larger doses of thebaine decreased responding in a dose-dependent fashion: $1.78 \mathrm{mg} / \mathrm{kg}$ reduced responding from $4.46 \pm 0.33$ (S.E.M.) resp/sec to $2.87 \pm 1.79 \mathrm{resp} / \mathrm{sec}$, while $3.2 \mathrm{mg} / \mathrm{kg}$ thebaine reduced responding to $1.35 \pm 0.59$ $\mathrm{resp} / \mathrm{sec}$.

Naloxone $(0.1$ and $1.0 \mathrm{mg} / \mathrm{kg})$ was administered concurrently either with 1.78 or with $3.2 \mathrm{mg} / \mathrm{kg}$ thebaine to determine whether these rate-suppressing effects could be antagonized. These doses of naloxone alone reduced slightly response rates from those observed with saline controls. Fig. $1 \mathrm{~b}$ shows that neither dose of naloxone reversed the ratesuppressing effects of either 1.78 or $3.2 \mathrm{mg} / \mathrm{kg}$ thebaine. Clearly, naloxone did not antagonize the effects of thebaine on operant responding for food; rather it may have slightly augmented the rate-reducing effects of thebaine. Morphine reduced $F R$ responding to $0.32 \mathrm{resp} / \mathrm{sec}(\mathrm{N}=4)$; naloxone reversed these effects completely (4.20 resp/sec; $N=4$ ).

\section{EXPERIMENT 2: THEBAINE SELF-INJECTION- SUBSTITUTION FOR CODEINE}

\section{METHOD}

Three monkeys with experimental histories of codeine self-injection were permanently housed in open-faced cubicles equipped with 2 response levers and an array of stimulus lights. The animals were restrained in these cubicles by a harness and tubular stainless steel arm as described by Deneau et al. [1]. The animals' surgically implanted intravenous catheters were connected through their restraining arms to injector devices. The monkeys were conditioned to selfinject codeine on a fixed-ratio $30,10 \mathrm{~min}$ timeout procedure as described by Woods [10].

\section{RESULTS}

After responding for codeine had stabilized on this schedule, saline or thebaine in doses ranging from 0.003 to $1.0 \mathrm{mg} / \mathrm{kg} /$ injection was substituted for the codeine in single experimental sessions. The animals uniformly took all the codeine injections available to them during the session (a maximum of 13). When saline was substituted for codeine, the average number of injections taken per session decreased to $8.4 \pm 1.3$ (S.E.M.). Substitution of thebaine produced no increase in the number of injections taken, except possibly for $1.0 \mathrm{mg} / \mathrm{kg} / \mathrm{inj}$ (10.1 infusions). Fixed-ratio response rates over most thebaine doses studied were no higher than those for saline, and in all cases, they were lower than those for 0.3 $\mathrm{mg} / \mathrm{kg}$ codeine (Fig. 2). Response rates during the time out period, while the drug pump was running, or those associated with the non-drug lever did not vary significantly under the various conditions of codeine, saline, and thebaine selfinjection.

\section{EXPERIMENT 3: THEBAINE SELF- ADMINISTRATION UNDER UNLIMITED ACCESS AND ITS INTERACTION WITH NALOXONE}

\section{METHOD}

Four naive monkeys were prepared with intravenous catheters. These monkeys were permanently housed in sound-attenuating wooden cubicles, each equipped with a 

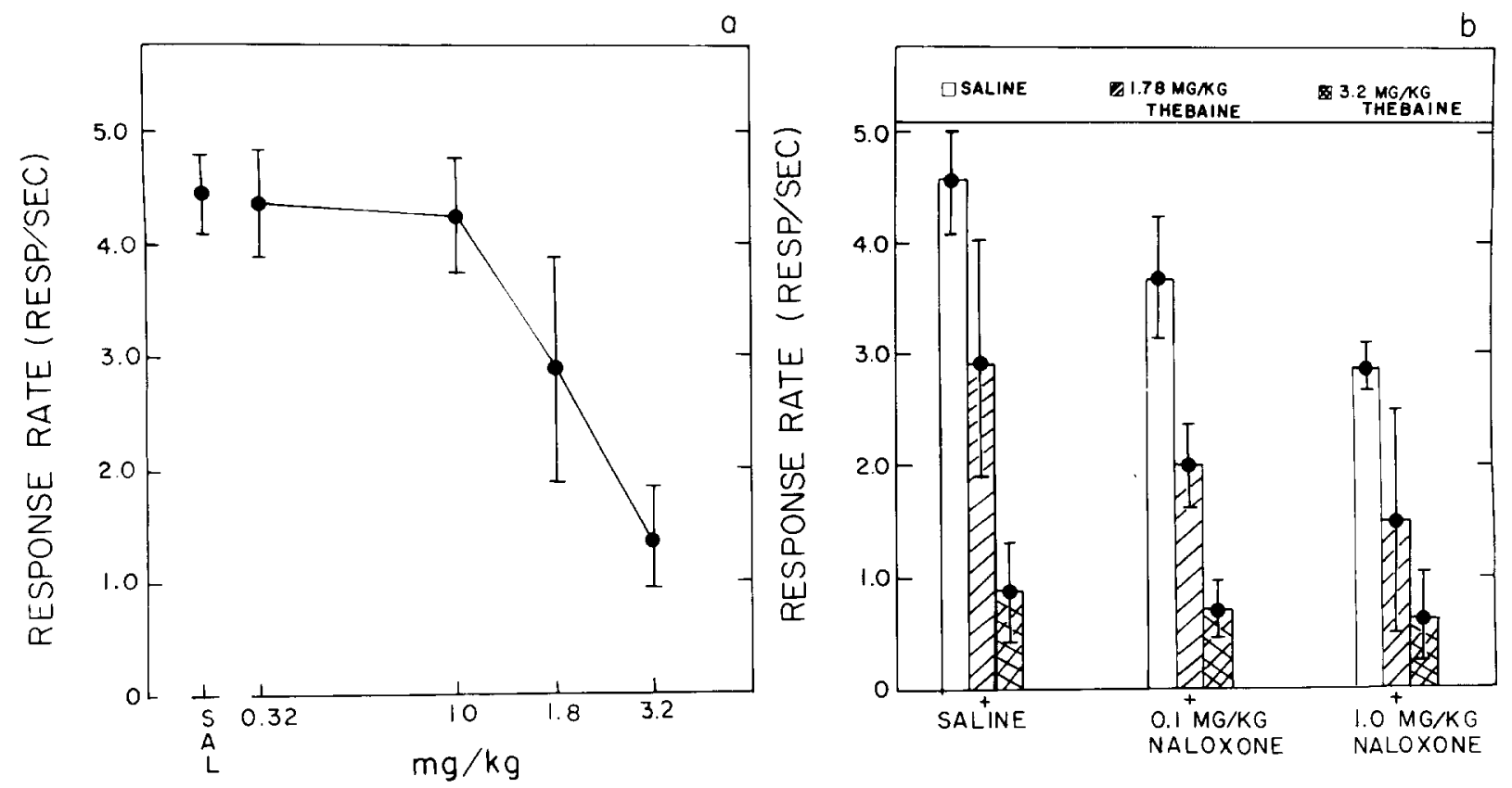

THEBAINE

FIG. 1. (a) The effects of thebaine on FR response rates. Each point is the mean of 8 observations (2 determinations in 4 monkeys). Abscissa: dose, $\mathrm{mg} / \mathrm{kg}$ (log scale). Ordinate: response rate (resp/sec) during the FR portion of the schedule. SAL: saline control. Vertical bars: S.E.M. $(\mathrm{N}=4)$. FIG. 1. (b) The effects of saline or thebaine administered concurrently with either saline or naloxone. Abscissa: The three bars on the left indicate saline, $1.78 \mathrm{mg} / \mathrm{kg}$ thebaine and $3.2 \mathrm{mg} / \mathrm{kg}$ thebaine administered with saline. The three bars in the middle indicate the same three doses administered with $0.1 \mathrm{mg} / \mathrm{kg}$ naloxone; the three on the right, with $1.0 \mathrm{mg} / \mathrm{kg}$ naloxone. Ordinate: response rate (resp/sec) during the FR portion of the schedule. Vertical bars: $S . E . M$. (N=4).

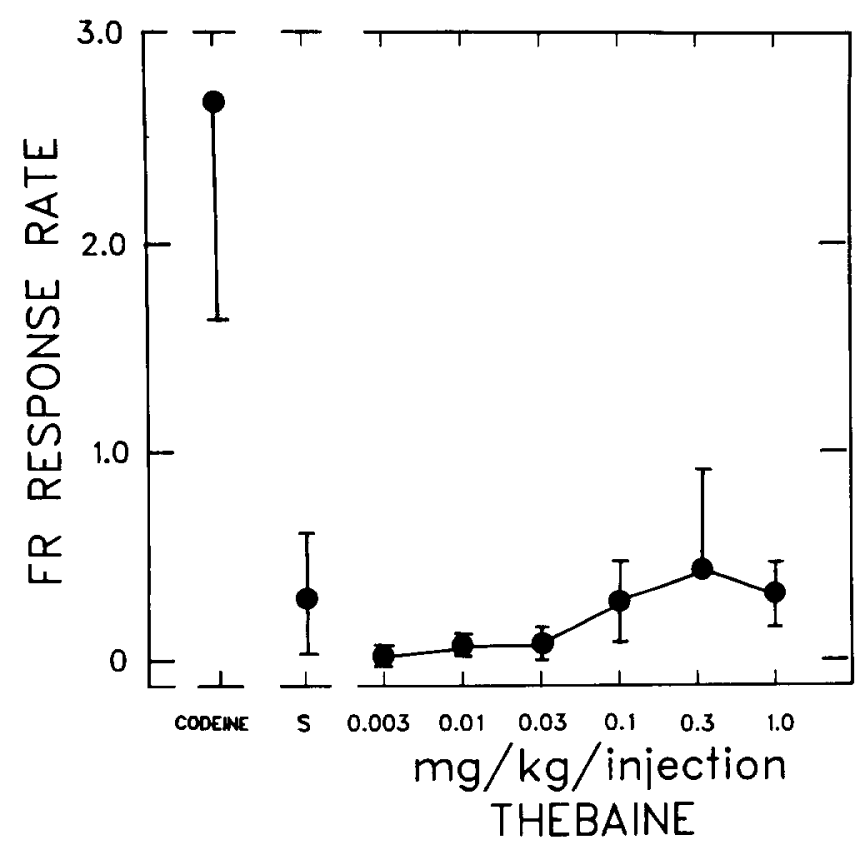

FIG. 2. Fixed-ratio 30 response rate maintained by codeine $(0.3$ $\mathrm{mg} / \mathrm{kg} / \mathrm{inj})$, saline, and thebaine $(0.003-1.0 \mathrm{mg} / \mathrm{kg})$. Each dose of thebaine and saline was evaluated twice in each of three monkeys. Codeine was used to maintain the performance and six sessions were randomly chosen and averaged for comparison. Brackets indicate the standard error of the average $(\mathrm{N}=3)$. drug infusion pump, houselights, and two response levers with stimulus lights. The animals were restrained within their cubicles with stainless steel spring arms and harnesses as described by Schuster and Johanson [8].

Monkeys were allowed 23 hours per day continuous access to saline. Each response on the designated lever (FR 1) delivered a $10 \mathrm{sec}$ injection of saline, during which the houselights were turned off and a red injection light was turned on. Saline was available for the first seven days following surgery.

Thebaine (ethanoate or HCL), $1.0 \mathrm{mg}$ base $/ \mathrm{kg} /$ injection, was substituted for saline on the eighth day and its availability continued on the FR 1 until the animals" intake stabilized (2-5 weeks). A single monkey (no. 93) was given hourly injections $(1 \mathrm{mg} / \mathrm{kg}$ ) for five consecutive days after a week of exposure to the drug during which responding was not initiated. Following stabilization of responding maintained under the FR 1 schedule, the fixed ratio values were increased from 1 to 3,5 , and finally 10 at intervals of approximately 5 days for all animals.

Under the FR 10 schedule, a single administration of 0.1 , 0.3 , or $1.0 \mathrm{mg} / \mathrm{kg}$ naloxone was given at 3-4 day intervals in mixed order. Changes in thebaine self-injection were recorded and gross changes in behavior were observed consequent to naloxone administration. Saline was substituted for thebaine and changes in self-injection responding were recorded and observable signs of behavioral change noted over a four day period.

In two monkeys, codeine was subsequently made avail- 


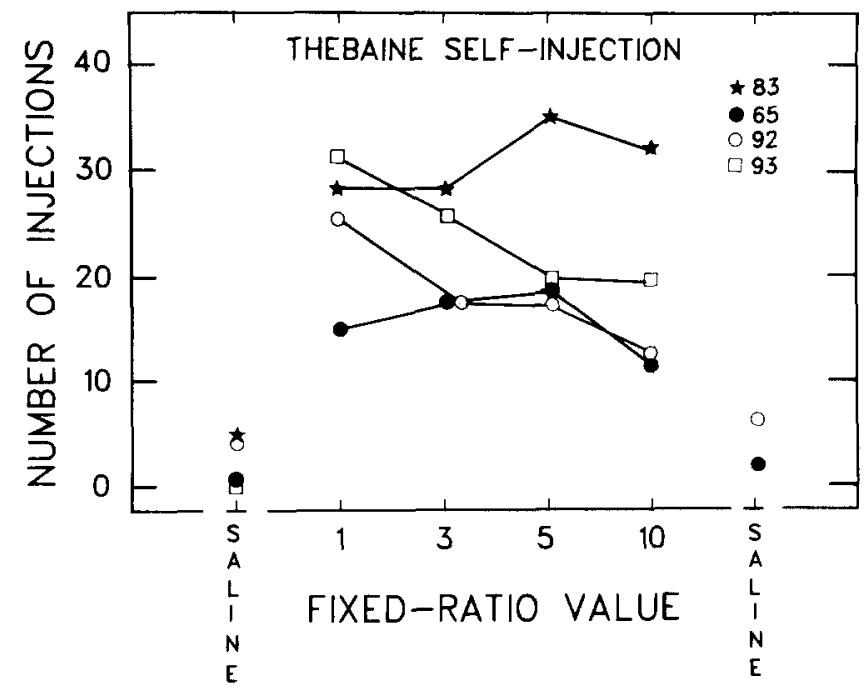

FIG. 3. Mean number of $1.0 \mathrm{mg} / \mathrm{kg}$ thebaine infusions taken during the last three days at various fixed ratio values in Experiment 3 . S: saline infusions taken on FR I schedule before thebaine was introduced. $S_{2}$ : saline infusions taken on an FR 10 schedule after thebaine was discontinued. Numbers in parentheses indicate mean number of days at each ratio value.

able at a dose of $2.0 \mathrm{mg} / \mathrm{kg} / \mathrm{inj}$ at FR 10 under $23 \mathrm{hr}$ access conditions. Subsequent to two weeks of exposure, the same doses of naloxone were given and changes in observable behavioral signs were noted and changes in self-injection responding were recorded.

\section{RESULTS}

The monkeys took between 0 and 5 infusions of saline per $23 \mathrm{hr}$ session (Fig. 3). When thebaine was substituted for saline, three of the four monkeys spontaneously increased responding until they were taking an average of 22.7 injections/session. The fourth monkey, animal no. 93, did not self-inject thebaine until hourly infusions of the drug were programmed for five consecutive days. After these noncontingent injections she began responding for thebaine at a rate similar to that of the other animals. When the FR re- quirement was increased from 1 to 10 , the average number of injections/session for all monkeys decreased slightly to 18.9 . FR responding was of the typical break and run pattern [2].

The three monkeys were given IM doses of naloxone on different days immediately before the start of a daily session. The first monkey, no. 83 , received $1.0 \mathrm{mg} / \mathrm{kg}$ naloxone as her first dose. Within $25 \mathrm{~min}$ of the naloxone injection, she began lying down, was hyper-irritable and retching. The animal did not increase responding for thebaine during the period following the naloxone injection, but her responding on the non-drug lever greatly increased from the average of 3 responses/session to 35 in the first hour of the naloxone pretreatment session. Two hours later the animal was no longer hyper-irritable or retching, but was lying down and showing tension. The monkey was observed for four hours after the naloxone injection, at which time these physical signs had subsided. She was found dead in her cubicle the next morning, clearly not from convulsions, since no contusions or abrasions were noted.

The two remaining monkeys, no. 92 and no. 65 , completed their series of naloxone injections and, as can be seen from Table 1, in no case did thebaine intake increase either during the first hour of the session after the injection or during the entire $23 \mathrm{hr}$ session. Rather there was either no change or decreases in intake over these time periods. Furthermore. neither animal showed signs of gross behavioral change at any dose of naloxone. After completing this series of naloxone injections, saline was substituted for thebaine in each animal and responding declined over several sessions to an average of 2 to 6 infusions of saline per day (Fig. 3). Neither monkey showed any signs of gross behavioral change when the substitution was made.

As a comparison experiment, with monkeys no. 93 and no. 65 , codeine $(2.0 \mathrm{mg} / \mathrm{kg} /$ infusion $)$ was then substituted for saline. Within 3 days, monkey no. 65 began taking between 10 and 20 infusions of codeine per day, and within two weeks the intake had increased to an average 130 infusions per day. At this point she died of non-experimentally related causes. The second codeine-exposed monkey, no. 92, also increased responding for codeine until he was taking an average of 56 infusions per $23 \mathrm{hr}$ session. After codeine intake had stabilized, he was then pretreated on different days with 0.1 . 0.3 , or $1.0 \mathrm{mg} / \mathrm{kg}$ of naloxone. He showed mild signs of withdrawal at the two lower doses (excessive vocalizations, mild irritability) and more severe symptoms (extreme irritability

TABLE 1

THEBAINE, CODEINE, AND THEIR INTERACTIONS WITH NALOXONE ON SELF-INJECTION RESPONDING

\begin{tabular}{|c|c|c|c|c|c|c|c|c|}
\hline \multirow[t]{3}{*}{$\begin{array}{c}\text { Naloxone } \\
\text { Dose } \\
(\mathrm{mg} / \mathrm{kg})\end{array}$} & \multicolumn{6}{|c|}{$\begin{array}{l}1.0 \mathrm{mg} / \mathrm{kg} \\
\text { Thebaine }\end{array}$} & \multirow{2}{*}{\multicolumn{2}{|c|}{$\begin{array}{c}2.0 \mathrm{mg} / \mathrm{kg} \\
\text { Codeine } \\
\text { No. } 92\end{array}$}} \\
\hline & \multicolumn{2}{|c|}{ No. 83} & \multicolumn{2}{|c|}{ No. 65} & \multicolumn{2}{|c|}{ No. 92} & & \\
\hline & Hour 1 & 23 Hours & Hour 1 & 23 Hours & Hour 1 & 23 Hours & Hour 1 & 23 Hours \\
\hline Saline & $4^{*}$ & 36 & 3 & 18 & 1 & 12.5 & 5.7 & 55.7 \\
\hline 0.10 & - & - & 4 & 4 & 2 & 7 & 10 & 34 \\
\hline 0.30 & - & - & 0 & 8 & - & - & 3 & 49 \\
\hline 1.0 & 3 & death & $0 / 1^{+}$ & $4 / 14$ & 1 & 10 & 4 & 62 \\
\hline
\end{tabular}

* Number of infusions.

$\dashv$ This dose was tested twice in animal No. 65 . 
and activity, bizarre postures, retching) at the $1.0 \mathrm{mg} / \mathrm{kg}$ dose. The animal did not significantly change his codeine intake after nay of the naloxone pretreatments either in the first hour or during the rest of the post-naloxone sessions (Table 1).

\section{GENERAL DISCUSSION}

Thebaine self-injection was maintained under 23-hr unlimited access conditions, but, under the FR 30 timeout 10 min schedule, the rate of responding was only marginally above that generated by the saline vehicle (Figs. 2 and 3 ). Yanagita and Miyasato [13] reported similarly that selfinjection of thebaine under 4-hr access, FR 1 was only marginally above saline; however, under unlimited access FR 1 conditions, both we and Yanagita and his colleagues found that 0.1 to $1.0 \mathrm{mg} / \mathrm{kg}$ would maintain stable levels of responding above vehicle. It is likely that these same patterns of self-injection will be found across different contingencies with other drugs, e.g., barbiturates and benzodiazepines $[5,15]$, and clonidine [11]. There are at least two potiential explanations for the difference in self-injection results under different access conditions. One is that cost/reinforcement as defined by response requirement and availability differ in a functional way between the two conditions. A second possibility is that weak reinforcers maintain behavior only slightly above their vehciles. Compared over short periods of exposure the difference may be insignificant; with longer exposure, smaller differences become relatively more important.

Thebaine is a close chemical congener of codeine and morphine but its acute and chronic effects differ significantly from them. In the monkey, at doses of $4-8 \mathrm{mg} / \mathrm{kg}$, thebaine produced tremor, restlessness, hyper-irritability, and slight motor impairment [13]; note that these doses are larger than those necessary to completely suppress food-reinforced responding (Fig. 1). In the dog, Gilbert and Martin [4] reported that thebaine did not produce any morphine-like effects in nondependent dogs. Yanagita and Miyasato [13] reported that the effects of thebaine, rather than substituting for those of morphine, resembled to some extent the withdrawal syndrome produced by morphine antagonists. The signs observed in the dependent and nondependent monkey were discriminably different. This was not found to be the case in dogs, in that thebaine produced signs that were comparable in kind and magnitude in morphine-dependent and nondependent dogs [4].

Nevertheless, there are some common actions of thebaine and morphine. At appropriate doses, these compounds produce rate reductions of food-reinforced responding. In higher doses in rodents they will induce convulsions. These common actions may be mediated by different mechanisms since naloxone has the capacity to antagonize morphine's actions to a far greater extent than those of thebaine in either species (Fig. 1; [3]).

Thebaine has been shown not to produce a deprivationwithdrawal syndrome following its chronic administration to either rats [6] or dogs [4]. Our findings are in agreement; on the other hand, Yanagita and Miyasato [13] found in rhesus monkeys both deprivation and antagonist-induced withdrawal syndromes. In one of the three monkeys in the present experiment, naloxone produced a strong reaction culminating in death. It is of interest to note that this animal was self-administering larger amounts (ca. $30 \mathrm{mg} / \mathrm{kg} / \mathrm{day}$ ) than the two monkeys that showed no reaction to naloxone. These data taken together with those of Yanagita and Miyasato [13] suggest dependence may develop, and that it should be studied further under conditions involving over $30 \mathrm{mg} / \mathrm{kg} / \mathrm{day}$ of thebaine intake.

The findings of the present study, in general, agree with those cited above in showing that there are a number of acute actions of thebaine that are unlike those of morphine. The question of thebaine dependence requires further consideration; Yanagita et al. [14] have suggested that an active metabolite of thebaine, oripavaine may play a role in thebaine's dependence-producing capacity. Oripavaine has been found by Yamazoe et al. [12] in the urine of thebainetreated monkeys. This compound should be examined directly to determine whether its potency is sufficient to account for the dependency produced by thebaine.

\section{REFERENCES}

1. Deneau, G. A., T. Yanagita and M. H. Seevers. Selfadministration of psychoactive substances by the monkey-a measure of psychological dependence. Psychopharmacologia 16: $30-48,1969$.

2. Ferster, C. B. and B. F. Skinner. Schedule's of Reinforcement. New York: Appleton-Century-Crofts, 1957.

3. Gilbert, P. E. and W. R. Martin. Antagonism of the convulsant effects of heroin, d-propoxyphene, meperidine, normeperidine, and thebaine by naloxone in mice. J. Pharmac. exp. Ther. 192: 538-541, 1975.

4. Gilbert, P. E. and W. R. Martin. The pharmacology of thebaine in the chronic spinal dog. Drug Alcohol Depend. 3: 139-142, 1978.

5. Hackett, D. and J. M. Hall. Reinforcing properties of intravenous diazepam in rhesus monkeys (macaca mulatta) with a history of codeine self-administration. In: Clinical Toxicology, Proceedings of the 18th meeting of the European Society of Toxicology, edited by H. A. Duncan. Amsterdam/New York: Excerpta Medica, 1977, pp. 308-310.

6. Harris, L. Cited in: The dependence potential of thebaine. Bull. Narcot. 32: 45-54, 1980.

7. Jaffe, J. H. and W. R. Martin. Narcotic analgesics and antagonists. In: The Pharmacological Basics of Therapeutics. edited by L. S. Goodman and A. Gilman. New York: Macmillian, 1975, pp. 245-283.
8. Schuster, C. R. and C. E. Johanson. The use of animal models for the study of drug abuse. In: Research Advances in Alcohol and Drug Problems, Vol. I, edited by R. J. Gibbins, U. Israel, H. Kalant, R. E. Popham, W. Schmidt and R. G. Smart. New York: Wiley and Sons, 1974, pp. 1-31.

9. Shannon, H. E. and S. G. Holtzman. Evaluation of the discriminative effects of morphine in the rat. $J$. Pharmac. cxp. Ther. 198: $54-65,1976$

10. Woods, J. H. Narcotic-reinforced responding: A rapid evaluation procedure. Drug Alcohol Depend. 5: 223-230, 1980.

11. Woolverton, W. L., W. D. Wessinger, R. L. Balster and L. S. Harris. Intravenous clonidine self-administration by rhesus monkeys. Problems of Drug Dependence 1980. NIDA Research Monograph. 1980, in press.

12. Yamazoe, Y., R. Kato, H. Numata and T. Yanagita. Thebaine metabolites in the urine of rhesus monkeys. Folia pharmac. jap. 75: $143,1979$.

13. Yanagita, T. and K. Miyasato. Dependence studies on thebaine in rhesus monkeys. Jap. J. Pharmac. 28: Suppl. 62, 1978.

14. Yanagita, T., K. Miyasato, N. Oooinuma and H. Kiyohara. Dependence potential of drotebanol, codeine and thebaine tested in rhesus monkeys. Bull. Narcot. 29: 33-46, 1977.

15. Yanagita, T. and S. Takahashi. Dependence liability of several sedative-hypnotic agents evaluated in monkeys. J. Pharmac. exp. Ther. 185: 307-316, 1973. 